Estudios de Administración, vol. 14, No 1, 2007, pp. 1-21

\title{
Logo Selection and Modification Guidelines: an empirical international validation in Chile
}

\author{
Sergio Olavarrieta S. \\ Facultad de Economía y Negocios \\ Universidad de Chile \\ Escuela de Economía y Negocios \\ Universidad Diego Portales \\ sergio.olavarrieta@udp.cl
}

\section{Roberto Friedmann}

The University of Georgia

bfriedmann@terry.uga.edu

\begin{abstract}
Logo selection and modification is a common marketing practice; brand managers and other marketing executives will normally face these kinds of decisions. However, logo design and modification have been largely neglected in the marketing literature. Few studies have empirically tested the effects of logo design characteristics on consumer responses (see Henderson and Cote 1998). In this paper, we set out to extend this research and guidelines to an international setting. This is thought to be particularly important, because in today's environment, brand strategy decisions often need to take into consideration the potential of expanding and competing globally, and brand elements can be perceived quite differently. In particular, our study replicates the cited work in a developing Latin-American country (i.e., Chile), to test the cross-cultural relevance and stability
\end{abstract}


of US-based logo guidelines in the context of a developing LatinAmerican nation with a vibrant marketplace.

Keywords: Logos, brands, symbols, Latin America, Chile.

Resumen

La elección y modificación de logos es una tarea común en marketing. Los gerentes de marca y otros ejecutivos de marketing enfrentan de forma regular este tipo de decisiones. Sin embargo, el diseño de logos y su modificación es un área que ha estado bastante ausente en la literatura de marketing. Pocos estudios han testeado el efecto de las características de diseño de los logos en la respuesta de los consumidores (ver Henderson y Cote 1998)). En este artículo se busca extender ese estudio a un escenario internacional. Esto parece de relevancia, si se considera que en el contexto competitivo actual las decisiones estratégicas de marcas deben muchas veces considerar las opciones de extenderse y competir globalmente, y los elementos de la marca, como el logo, pueden ser percibidos de maneras muy diferentes. En particular, este estudio replica la investigación mencionada en un país en desarrollo latinoamericano como Chile, de modo de poder testear la relevancia y estabilidad cross-cultural de las guías de diseño basadas en EE.UU. en el contexto de una nación en desarrollo con un mercado creciente y vibrante.

Palabras clave: Logos, marcas, símbolos, América Latina, Chile.

\section{Introduction}

In recent years, many large companies have decided to refresh their images by changing or updating their logos and brand name typeface. In the fast food industry, for example, Pizza Hut, Burger King, KFC and Hardee's have made changes to their logotypes. British Airways has "stylized" its traditional bird based logo, and changed the paint motives in its airplanes. Delta Airlines and Lan Chile -the premier Chilean airline- also "updated" their logo and painting designs, trying to appeal to a global market. In the 
consumer product markets, brand managers often deal with approving logos for new product launches, new logos for adapted or new packaging alternatives, and logo changes for the revitalization efforts of existing yet maturing brands. Therefore, logo selection and modification, is indeed a very common practice in today's competitive environment. Increased competition, globalization, and also the ease of changing designs due to advances in computer graphic design, have also made logo and image changes a more common activity than was the case historically.

The importance of brand elements (e.g., brand name, logo, slogan, brand character, etc.) as generators of awareness and image, has been widely acknowledged in the branding literature (e.g., Aaker 1991, Keller 1992, 1998) and marketing textbooks. Some studies have provided evidence for the value of well designed logos. For example Schechter in the US (1993) found that 55\% of logos tested made a significant difference in terms of image communication and brand recognition. However $45 \%$ of logos, made not difference at all compared to a baseline situation, where just the name of the brand was shown. Schechter (1993) did find some general associations, like letter based and character logos producing higher recognition scores compared to abstract logos, or that pictorial logos ("those suggestive of a recognizable object") producing higher scores on image contribution. However, he was cautious, indicating that it is difficult to base logo decisions on generalities, mostly given some design characteristics, may work for a particular desired output but not for another. Additionally, within logo categories (e.g. pictorial vs. letter based) one can also find differences, that may be caused by design characteristics, execution, category fit, "time or trend" fit, and other unique features of a given logo. However, the use of experimental and quasi experimental techniques to obtain a less subjective assessment of the effects of logo design characteristics is key to improve the effectiveness of branding strategies.

Despite these scattered efforts, branding research in the marketing arena has focused mainly on the brand name and on 
advertising, as the major generators of consumer responses to brands, somewhat neglecting other brand elements, particularly design or aesthetic related elements like logos, shapes and colors (Henderson 1998, Madden et al. 2000). The relevance of the research needed on these other brand elements (e.g., logo, colors, sound ) is supported, at the very least at face value, by the fact that brand communications are heavily based on visual images and expressions. Colors, shapes, intensities, designs, all mix together with logos and brand names, to convey brand meaning and affect brand perceptions and associations as can be the case with brand awareness and brand image. Bloch, Brunel and Arnold (2003) have validated a measure of the centrality of visual product aesthetics (CVPA), acknowledging that an important segment of consumers have moderate to high concern regarding product aesthetics.

Moreover, international and cross cultural investigation of these aesthetic based brand elements is specially important, given that the interpretation of those symbols by consumers, are heavily based on cultures and traditions.

So what should brand managers do when they face logo creation or modification decisions? What are some knowledge-based guidelines as opposed to gut-feeling guidelines that they can use in order to make those decisions? Should they always obey the desires of creative staff and designers in advertising and graphic-web design agencies? Would Latin American, and particularly southern cone designers and brand managers be safe considering the "logo recommendations" of US based studies (i.e. Schechter 1993, Simonson and Marcus 1995, Henderson and Cote 1998).

Recently, some researchers have made contributions to this matter. Henderson and Cote (1998), specifically addressed the issue of logo design and modification, finding certain patterns and guidelines that may be useful for brand managers when facing logo decisions. Some of their findings suggest that: particular shapes, repetition of elements, and the degree of abstraction of the design, among other design elements, can have important effects on brand 
affect, image and recognition. These guidelines are a big help for designing and modifying logos for the local market. However, with so many companies going international, anywhere from canned foodstuffs to banking and financial services, the issues and decisions pertaining logo selection and modification, would be greatly enhanced taking into account their effect on global market consumers. Examples of the questions one could consider are: what does the Jolly Green Giant represent, if anything, in Argentina? Would people in Latin cultures like a round and naturalistic logo -e.g., a "stylized" Panda Bear- the same than US consumers? Do people react similarly to Nike's "swoosh" in Western developed nations as they do in Latin-American countries? Does the Michelin tire-character generate the same brand associations in France as it does in Mexico?

In this paper we extend Henderson and Cote's (1998) research to an international setting. This is thought to be important, for in today's environment many of a brand's strategic alternatives and brand elements decisions need to take into consideration the potential to expand and compete globally. There already is some observational and empirical evidence that Latin-American consumer behavior varies relative to US consumers' behavior (see for example: Nicholls et al 2000). In particular, we replicated the study in a developing country such as Chile, to test the cross-cultural relevance and stability of US-based logo guidelines in the context of a developing Latin-American nation. Chile provides a good setting for testing the stability of previous findings, because it is a developing nation, with a very stable and open economy, and represents (as manifested by the large number of recent corporate arrivals) a typical target market for expanding multinational corporations. Additionally, most of the other developing nations in the region -the Southern Cone- have been following the same development strategy started by Chile during the $70 \mathrm{~s}$ and $80 \mathrm{~s}$. Results presented in this study should be considered as a first step and not as a final decision-making criteria, since more studies of this 
type need to be performed, with a broader range of logos and subjects.

\section{Review of the Literature: Identification and definition of Dependent and I ndependent Variables}

Brand elements, including: brand name, logo, slogan, colors, jingles and characters, can be considered as important determinants of brand awareness and brand image (Keller 1998; Schmitt 2000). In other words, according to the literature, brand elements, particularly brand visual elements, can help the creation and enhancement of brand equity if they fulfill several characteristics. Logos are particularly important because they are included in advertising, brochures, packaging, promotional material, sponsorships, and several other marketing communications. According to the literature, "good" logos should be recognizable, familiar, elicit appropriate and consensual meanings in the target market and generate positive affect in consumers (Robertson 1989, Giberson and Hulland 1994, Peter 1989).

\section{The Characteristics of Good Logos: Recognizable, conveyor of Meaning, generator of Affect, and Provider of a sense of Familiarity}

Because visual cues can speed-up perception and information retrieval, good logos improve the speed of recognition of a brand in different settings: in alternative selection and evaluation, actual shopping situations, ads, events, net surfing, yellow pages searching, etc. There are two types of recognition: correct and false. Correct recognition of the logo, represents the fact that consumers remember seeing the logo (which they have, in fact, seen before), and they then associate that logo to the correct brand. False recognition occurs 
when people think they have seen the logo, but in fact they have not. This may happen, due to the "familiarity" of the design, or the use of special visual cues that are familiar to the consumer or when the logo is associated with a competitive brand.

Brands are more valuable when they establish relationships with the consumers. These relationships are certainly enhanced when positive affect toward the brands is developed by consumers. Logos can help in the process of affect generation, because positive affective reactions toward the logo may transfer from the logo to the brand (similar to the way in which attitude toward the ad can transfer to attitude toward the brand).

Brand elements and logos can not only affect brand awareness, but they also can affect brand image and meaning. Brand image can be defined as the set of brand associations stored in consumers' minds. The combination of these associations and the interrelation of them with consumers' values, expectations and desires, will help the process of meaning generation. Logos can help this process when the adequate meanings are generated (i.e., the right associations), and when those meanings are consistent across the market. Clear meaning generation can help the linkage of the stimulus to the source (company or brand).

Logos can also help the creation of a sense of familiarity with the brand. Some logos are seen for the first time, and they immediately establish themselves in consumers' minds through the sense of familiarity that they evoke (even, if they have not been seen before). This is what Henderson and Cote call "subjective familiarity". This variable can be very important, because it can help the generation and transfer of positive affect to the brand (Zajonc 1968). 


\section{Logo Design Variables}

Four desired logo responses were identified in the previous section: recognition, positive affect, consensual meaning, and subjective familiarity. The question now, is how can marketers affect these response variables using logo design. Through a very thorough literature review and experts interviews, Henderson and Cote (1998) came up with a list of 11 logo design characteristics that are described below.

\section{A. Natural}

Reflects the degree to which the design depicts commonly experienced objects. It is comprised of two dimensions: representative and organic.

- Representative captures the degree of realism in a design. Abstract is the opposite endpoint of representative.

- Organic designs are those that are made up o natural shapes such as irregular curves. Geometric designs, tend to represent less natural, more synthetic-looking objects.

B. Harmony in the design

Represents a congruent pattern or arrangement of parts that combines symmetry and balance.

- Symmetric designs are those that appear as reflections along one or more axis. 
- Balance captures the notion that there is a center of suspension between two weights, or portions of the design.

C. Elaborate design

Captures the concept of design richness, and the ability to use simple lines to capture the essence of something. It is comprised of complexity, active and depth.

- Complexity arises from the number of elements in the design, the heterogeneity of elements, the irregularity in the arrangements of elements and how ornate the design is in and of itself.

- Active refers to the sensation of movement or flow provided by the design.

- Depth gives the appearance of perspective or a three dimensional design.

The remaining design characteristics were:

- Parallel: addresses the multiple lines or elements that appear adjacent to each other.

- Repetition of elements occur when the parts of the design are similar or identical to one another.

- Proportion represents the proportion between the horizontal and vertical dimensions.

- Round designs are made of primarily curved lines and circular elements. 


\section{Method}

This study follows the method used by Henderson and Cote (1998). We used unfamiliar logo designs (selected from "World Trademarks: 100 Years"), multiple samples, and different survey instruments to obtain the data. Despite we replicate the entire research procedure, there is a need for further studies to validate or complement these results. The readers should consider this phase as a exploratory stage in the research of aesthetic elements of the brand.

Three pre-tests were conducted in order to choose the stimulus and develop the final survey instruments. Three different samples were used in the study. Sample 1 included 60 college students who rated 33 logos each in terms of the following semantic differential scales: good/bad, interesting/not interesting, I like it/I do not like it, high quality/low quality, complex/simple. They also provided top-of-mind associations of the brand. These associations were used to compute three indicators of meaning: dominance (the most common association), entropy, and Hirschman-Herfindahl's measure of entropy ${ }^{1}$. Sample 2 included two sets of college students $(n=60)$, who assessed logo recognition. They were exposed to a Power Point slide-show where each logo was shown for two seconds. Fifteen minutes later, after a filler task, subjects answered if they remembered seeing each of a $66 \log$ os (33 that were actually shown, and 33 distractors). One week later, a second recognition task was conducted with the original 33 logos and 33 new distractors. These provided us two measures of recognition: recognition immediate after exposure and recognition one week after exposure

${ }^{1}$ For example, if after looking at a logo $50 \%$ of the subjects said it reminded them the sun, 30\% said a wheel, and 20\% said a star, dominance would be 0.5 . Entropy (measured using this formula: $-\Sigma \mathrm{p}_{\mathrm{i}} *$ In $\left(\mathrm{p}_{\mathrm{i}}\right)$ ) would have a score of 1.03. Finally, the Hirschman-Herfindahl index will be equal to the sum all squared probabilities. In this case: $0.25+0.09+0.04=0.38$. 
Sample 3 was an expert sample including two graphic designers who rated the 33 selected logos using the following semantic differential scales: active/non active, complex/simple, organic/inorganic, representative/unrepresentative, round/squared, symmetric/asymmetric, deep/shallow, durable/non-durable, balanced /unbalanced. Inter judge reliability was checked, finding consistency in the ratings, thus they provided the measures of the aestheticsubjective logo design variables.

Finally, the measures for the "quantitative" logo design variables such as: proportion, element repetition, and parallel lines, were computed by the authors.

\section{Results}

The measures of dependent and independent variables were first analyzed and reduced using exploratory factor analysis. The results are presented in Tables 1 and 2.

\section{Table 1}

Exploratory factor Analysis of Dependent Measures

(Logo Evaluation measures)

\begin{tabular}{|c|c|c|c|c|}
\hline VARIABLE & AFFECT & $\begin{array}{c}\text { FAMILIAR } \\
\text { MEANING }\end{array}$ & $\begin{array}{c}\text { CORRECT } \\
\text { RECOGNITION }\end{array}$ & $\begin{array}{c}\text { FALSE } \\
\text { RECOGNITION }\end{array}$ \\
\hline Good & $\mathbf{0 . 9 3 1}$ & 0.211 & 0.149 & -0.006 \\
\hline Quality & $\mathbf{0 . 9 2 2}$ & 0.115 & 0.008 & -0.141 \\
\hline Liking & $\mathbf{0 . 9 0 9}$ & 0.274 & 0.178 & -0.001 \\
\hline Interesting & $\mathbf{0 . 9 3 6}$ & 0.133 & 0.002 & -0.005 \\
\hline Distinctive & $\mathbf{0 . 6 8 3}$ & 0.364 & 0.346 & 0.004 \\
\hline Hirschman-Herfindahl & 0.150 & $\mathbf{0 . 9 3 0}$ & 0.001 & 0.009 \\
\hline Hirschman & 0.210 & $\mathbf{0 . 9 5 3}$ & 0.001 & 0.009 \\
\hline Entropy & 0.234 & $\mathbf{0 . 9 1 0}$ & 0.287 & -0.003 \\
\hline Familiarity & 0.234 & $\mathbf{0 . 9 0 7}$ & 0.004 & 0.005 \\
\hline Correct recognition Type1 & 0.180 & 0.155 & $\mathbf{0 . 9 1 9}$ & -0.131 \\
\hline Correct recognition Type 2 & 0.165 & 0.004 & $\mathbf{0 . 9 4 2}$ & 0.007 \\
\hline False recognition Type 1 & -0.002 & -0.145 & -0.001 & $\mathbf{0 . 9 2 7}$ \\
\hline False recognition Type 2 & -0.133 & 0.152 & -0.002 & $\mathbf{0 . 9 2 1}$ \\
\hline
\end{tabular}

Explained Variance $=89.866 \%$. 


\section{Table 2}

Factor Analysis of the Independent Measures (Logo design variables)

\begin{tabular}{|c|c|c|c|c|c|c|c|}
\hline Variable & Ellaborate & Natural & Harmony & Parallel & Proportion & Repetition & Round \\
\hline Active 1 & 0.899 & -0.162 & 0.008 & -0.005 & 0.184 & 0.205 & -0.001 \\
\hline Active 2 & 0.791 & 0.284 & 0.006 & -0.002 & 0.131 & 0.004 & 0.170 \\
\hline Complex1 & 0.909 & 0.003 & -0.192 & -0.0005 & 0.0003 & -0.155 & -0.166 \\
\hline Complex2 & 0.936 & 0.003 & -0.149 & 0.002 & -0.004 & -0.157 & -0.008 \\
\hline Depth 1 & 0.807 & -0.239 & 0.004 & 0.002 & 0.227 & 0.329 & 0.237 \\
\hline Depth 2 & 0.645 & 0.481 & 0.009 & 0.309 & -0.254 & 0.113 & -0.144 \\
\hline Organic1 & 0.00002 & 0.802 & -0.211 & 0.005 & 0.134 & -0.269 & -0.115 \\
\hline Organic2 & -0.004 & 0.784 & -0.250 & 0.148 & 0.006 & -0.180 & 0.126 \\
\hline Representative1 & 0.006 & 0.848 & -0.281 & -0.375 & 0.006 & $-0,208$ & -0.006 \\
\hline Representative 2 & -0.007 & 0.744 & $-0,249$ & -0.361 & 0.005 & -0.001 & -0.008 \\
\hline Balance 1 & -0.0002 & -0.206 & 0.779 & -0.148 & -0.303 & 0.140 & 0.110 \\
\hline Balance 2 & -0.002 & -0.203 & 0.871 & -0.208 & 0.004 & 0.002 & -0.147 \\
\hline Symmetry 1 & 0.251 & $-0,210$ & 0.700 & 0.331 & -0.004 & 0.007 & 0.008 \\
\hline Symmetry 2 & 0.004 & $-0,383$ & 0.820 & -0.006 & -0.005 & 0,118 & 0.009 \\
\hline Parallel 1 & 0.001 & -0.001 & -0.007 & 0.956 & 0.157 & 0.001 & -0.154 \\
\hline Parallel 2 & 0.003 & -0.001 & -0.008 & 0.956 & 0.149 & 0.001 & -0.144 \\
\hline Proportion1 & 0.116 & 0.008 & -0.009 & -0.120 & 0.935 & -0.004 & -0.234 \\
\hline Proportion2 & 0.125 & 0.009 & -0.123 & -0.186 & 0.937 & 0.001 & -0.139 \\
\hline Round 1 & -0.006 & -0.150 & 0.0001 & -0.243 & -0.193 & 0.0001 & 0.813 \\
\hline Round 2 & 0.006 & 0.009 & 0.005 & -0.006 & -0.151 & -0.003 & 0.903 \\
\hline Repetition 1 & -0.008 & -0.153 & 0.109 & -0.003 & 0.005 & 0.948 & -0.005 \\
\hline Repetition 2 & 0.185 & -0.284 & 0.143 & 0.009 & -0.106 & 0.878 & 0.001 \\
\hline
\end{tabular}

Explained variance $81.161 \%$.

Because of low common variance (commonalities), two independent variables (e.g., durable and cohesive) were eliminated in the process.

According to these results, seven common factors explained $81.61 \%$ of the total variance in the data. These factors were labeled: Natural, Harmony, Elaborate, Parallel, Round, Proportion y Repetition. Comparing the results of both factor analysis (dependent and independent measures), we found a strong consistency with the results of Henderson and Cote's study (1998). In fact, the factor analytical solutions had the same number of factors, explaining similar percentages of total variance, and more importantly, having consistent factor loadings of the variables on the factors, which indicates the presence of a cross-culturally stable factor structure. 


\section{A. The Effect of Design Variables on Logo Evaluations}

The next step of the study was to test the hypotheses that logo design variables will affect consumers' logo and brand evaluations. For this, we conducted several regression analysis using the factor scores from the previous analysis as the dependent and independent variables. Given experimental aesthetics suggests that visual elements will normally have non-linear effects on consumers' responses to designs (Berlyne 1971), and following Henderson and Cote (1988) procedure, we utilized the curve estimation program of SPSS for testing non-linear relationships. Therefore, we estimated quadratic, cubic, inverse and linear regression models to examine the statistical significance of effects of design variables. Each independent variable (e.g., factor scores) was regressed individually against the independent measures (factor scores of the logo design variables), using the most significant non-linear transformation as explained above. The main regression results are presented in the Table 3 through 6 . In each of these tables we present the regression coefficients for a particular dependent variable regression model. Significant logo design characteristics are highlighted in bold letters. The seven logo design factors explain $42.4 \%$ of the variance of False Recognition $(\mathrm{F}=1.720, \mathrm{p}=0.047), 46.9 \%$ of the variance of Familiar Meaning $(\mathrm{F}=2.425, \mathrm{p}=0.048), 74.3 \%$ of the variance of Affect $(\mathrm{F}=4.985, \mathrm{p}=0.001)$.

In Table 3 we present the results for Correct Recognition, where both Natural and Repetition, have significant and positive coefficients. Round has a significant but negative and squared relationship with correct recognition. This means that intermediate levels of "roundness" will be better for the correct recognition of a brand associated with a logo.

In Table 4 results for the False Recognition regression are presented. Here Round, has a negative and linear relationship, Elaborate has a squared and positive relationship, and Parallel has a squared and negative relationship with False Recognition. 
Table 3

Regression Model for Correct Recognition

\begin{tabular}{|l|c|c|c|c|c|}
\hline & $\begin{array}{c}\text { GENERAL FIT OF } \\
\text { THE MODEL }\end{array}$ & R2=0.603 & ADJ. R2 $=0.338$ & $\mathrm{~F}=2.278$ & $\mathrm{P}=0.046$ \\
\hline VARIABLES & $\begin{array}{c}\text { REGRESSION } \\
\text { COEFFICIENT }\end{array}$ & $\begin{array}{c}\text { STANDARD } \\
\text { ERROR }\end{array}$ & $\begin{array}{c}\text { STANDARDIZED } \\
\text { COEFFICIENT }\end{array}$ & $\mathrm{t}$ & $\mathrm{p}$ \\
\hline Elaborate & 0.019 & 0.172 & 0.019 & 0.110 & 0.913 \\
\hline Natural & $\mathbf{0 . 3 8 4}$ & $\mathbf{0 . 1 8 2}$ & $\mathbf{0 . 3 8 4}$ & $\mathbf{2 . 1 0 5}$ & $\mathbf{0 . 0 5 0}$ \\
\hline Harmony & 0.255 & 0.384 & 0.255 & 0.663 & 0.516 \\
\hline Harmony`2 & -0.408 & 0.228 & -0.395 & -1.792 & 0.090 \\
\hline Harmony`3 & -0.310 & 0.203 & -0.671 & -1.525 & 0.145 \\
\hline Parallel & 0.272 & 0.188 & 0.272 & 1.443 & 0.166 \\
\hline Proportion $^{\text {Proportion`2 }}$ & 0.579 & 0.312 & 0.579 & 1.857 & 0.080 \\
\hline Repetition & -0.208 & 0.104 & -0.668 & -2.007 & 0.060 \\
\hline Round & $\mathbf{0 . 3 5 4}$ & $\mathbf{0 . 1 7 9}$ & $\mathbf{0 . 3 5 4}$ & $\mathbf{1 . 9 8 2}$ & $\mathbf{0 . 0 3 3}$ \\
\hline Round ^2 & 1.431 & 0.405 & 1.431 & 3.533 & 0.002 \\
\hline Round 3 & $\mathbf{- 0 . 7 9 1}$ & $\mathbf{0 . 1 8 8}$ & $\mathbf{- 1 . 7 9 7}$ & $\mathbf{- 4 . 2 0 1}$ & $\mathbf{0 . 0 0 1}$ \\
\hline
\end{tabular}

$60.3 \%$ of the variance of Correct Recognition was explained by the seven design factors in this case $(\mathrm{F}=2.27, \mathrm{p}=0.046)$.

\section{Table 4}

Regression Model for False Recognition

\begin{tabular}{|l|c|c|c|c|c|}
\hline & $\begin{array}{c}\text { GENERAL FIT OF } \\
\text { THE MODEL }\end{array}$ & $\mathrm{R}^{2}=0.424$ & ADJ.R $\mathrm{R}^{2}=0.178$ & $\mathrm{~F}=1.720$ & $\mathrm{P}=0.047$ \\
\hline VARIABLES & BETA & $\begin{array}{c}\text { STANDARD } \\
\text { ERROR }\end{array}$ & $\begin{array}{c}\text { STANDARDIZED } \\
\text { COEFFICIENT }\end{array}$ & $\mathrm{t}$ & $\mathrm{p}$ \\
\hline Elaborate & $\mathbf{4} .735$ & 0.229 & -0.735 & -3.209 & 0.004 \\
\hline Elaborate $^{\wedge} \mathbf{2}$ & $\mathbf{0 . 4 0 3}$ & $\mathbf{0 . 1 7 7}$ & $\mathbf{0 . 5 4 6}$ & $\mathbf{2 . 2 7 7}$ & $\mathbf{0 . 0 3 3}$ \\
\hline Natural & .0 .194 & 0.182 & 0.194 & 1.065 & 0.299 \\
\hline Harmony & -0.287 & 0.180 & -0.267 & -1.485 & 0.152 \\
\hline Parallel & .0 .959 & 0.410 & 0.959 & 2.340 & 0.029 \\
\hline Parallel`2 & $\mathbf{- 0 . 3 1 8}$ & $\mathbf{0 . 1 4 0}$ & $\mathbf{- 0 . 9 5 6}$ & $\mathbf{- 2 . 2 7 7}$ & $\mathbf{0 . 0 3 3}$ \\
\hline Proportion & -0.031 & 0.185 & -0.031 & -0.166 & 0.869 \\
\hline Repetition & $\mathbf{- 0 . 0 3 9}$ & 0.166 & -0.039 & -0.236 & 0.816 \\
\hline Round & $\mathbf{4 . 2 8 2}$ & $\mathbf{0 . 1 6 9}$ & $\mathbf{- 0 . 2 8 2}$ & $\mathbf{- 1 . 6 6 7}$ & $\mathbf{0 . 0 3 5}$ \\
\hline
\end{tabular}

In Table 5, the Affect regression is presented. Repetition has a positive and significant coefficient. This is quite interesting, because normally, repetition has been suggested in the advertising literature as a key determinant of recall. Additionally, Harmony has inverted-U relationship (negative squared) relationship with affect, and Proportion has a U shaped relationship (positive squared). This implies that intermediate levels of proportion and harmony in logos, 
will have more positive and negative results on brand affect respectively.

Table 5

Regression Model for Familiar Meaning

\begin{tabular}{|l|c|c|c|c|c|}
\hline & $\begin{array}{c}\text { GENERAL FIT OF } \\
\text { THE MODEL }\end{array}$ & $\mathrm{R}^{2}=0.469$ & ADJ. $\mathrm{R}^{2}=0.275$ & $\mathrm{~F}=2.425$ & $\mathrm{P}=.048$ \\
\hline VARIABLES & BETA & $\begin{array}{c}\text { STANDARD } \\
\text { ERROR }\end{array}$ & $\begin{array}{c}\text { STANDARDIZED } \\
\text { COEFFICIENT }\end{array}$ & $\mathrm{T}$ & $\mathrm{p}$ \\
\hline Elaborate & .0 .285 & 0.157 & 0.285 & 1.809 & 0.084 \\
\hline Natural & -0.119 & 0.161 & -0.119 & -0.119 & 0.466 \\
\hline HARMONY & $\mathbf{. 0 . 2 1 9}$ & $\mathbf{0 . 1 6 0}$ & $\mathbf{0 . 2 1 9}$ & $\mathbf{1 . 3 6 9}$ & $\mathbf{0 . 0 4 2}$ \\
\hline Parallel & .1 .005 & 0.364 & 1.005 & 2.761 & 0.011 \\
\hline Parallel $\mathbf{2}$ & $\mathbf{- 0 . 2 8 2}$ & $\mathbf{0 . 1 2 6}$ & $\mathbf{- 0 . 8 4 8}$ & $\mathbf{- 2 . 2 4 7}$ & $\mathbf{0 . 0 3 8}$ \\
\hline PROPORTION & $\mathbf{0 . 5 1 5}$ & $\mathbf{- 0 . 1 7 1}$ & $\mathbf{- 0 . 5 1 5}$ & $\mathbf{3 . 0 0 2}$ & $\mathbf{0 . 0 0 7}$ \\
\hline Repetition & $-7.47 \mathrm{E}-02$ & 0.155 & -0.075 & -0.481 & 0.635 \\
\hline Round & $3.545 \mathrm{E}-02$ & 0.159 & 0.035 & 0.223 & 0.826 \\
\hline
\end{tabular}

Table 6 shows the results for Familiar Meaning. Harmony, is positively associated with Meaning, whereas Proportion is negatively associated. This means that the more harmonic the logo and the less proportionate the logo, the higher the familiar meaning consumers will derive from it. Additionally, "not so parallel" and very "parallel" logos will generate more familiar meaning that logos in the middle.

\section{Table 6}

Regression Model for Affect

\begin{tabular}{|l|l|c|c|c|c|}
\hline & $\begin{array}{l}\text { GENERAL FIT OF } \\
\text { THE MODEL }\end{array}$ & $\mathrm{R}^{2}=0.743$ & ADJ. ${ }^{2}=0.595$ & $\mathrm{~F}=4.985$ & $\mathrm{p}=0.001$ \\
\hline VARIABLES & $\begin{array}{l}\text { REGRESSION } \\
\text { COEFFICIENT }\end{array}$ & $\begin{array}{l}\text { STANDARD } \\
\text { ERROR }\end{array}$ & $\begin{array}{l}\text { STANDARDIZED } \\
\text { COEFFICIENT }\end{array}$ & $\mathrm{t}$ & $\mathrm{P}$ \\
\hline Elaborate & 0.154 & 0.135 & 0.154 & 1.141 & 0.288 \\
\hline Natural & 0.073 & 0.142 & 0.073 & 0.515 & 0.612 \\
\hline Harmony & 0.954 & 0.294 & 0.954 & 3.239 & 0.004 \\
\hline Harmony^2 $^{\wedge}$ & $\mathbf{- 0 . 2 4 8}$ & $\mathbf{0 . 1 6 4}$ & $\mathbf{- 0 . 2 4 0}$ & $\mathbf{- 1 . 5 1 2}$ & $\mathbf{0 . 0 4 7}$ \\
\hline Harmony`3 & 0.465 & 0.156 & 1.006 & 2.984 & 0.080 \\
\hline Parallel & -0.138 & 0.143 & -0.138 & -0.966 & 0.346 \\
\hline Proportion & 0.680 & 0.239 & 0.680 & 2.848 & 0.010 \\
\hline Proportion`2 $^{\wedge}$ & $\mathbf{0 . 1 8 1}$ & $\mathbf{0 . 8 0 0}$ & $\mathbf{0 . 5 8 0}$ & $\mathbf{2 . 2 5 1}$ & $\mathbf{0 . 0 3 6}$ \\
\hline Repetition & $\mathbf{0 . 3 6 0}$ & $\mathbf{0 . 1 3 5}$ & $\mathbf{0 . 3 6 0}$ & $\mathbf{2 . 6 7 2}$ & $\mathbf{0 . 0 1 5}$ \\
\hline Round & 0.157 & 0.121 & 0.157 & 1.293 & 0.212 \\
\hline Round 2 & -0.108 & 0.141 & -0.113 & -0.768 & 0.452 \\
\hline
\end{tabular}


B. Chile vs US (Henderson and Cote 1998) Results

The particular significant effects of design characteristics on response variables and shape of the relationship are summarized in part a) of Table 7 . These results show that, as suggested by several brand strategists and confirmed by Henderson and Cote (1998), logo design characteristics do affect consumer responses in terms of correct and false recognition, meaning and affect. Additionally, another interesting finding is that each of the different characteristics can affect different responses. In other words, in order to generate the adequate consumer responses, marketing managers, advertising experts and designers need to consider and manipulate all seven different logo design factors in particular ways.

Table 7

Summary of Chile and US Results (Henderson and Cote, 1998)

\begin{tabular}{|c|c|c|c|c|c|c|c|c|}
\hline \multirow[b]{2}{*}{$\begin{array}{l}\text { RESPONSE } \\
\text { VARIABLE }\end{array}$} & \multicolumn{4}{|c|}{$\begin{array}{c}\text { PART A) } \\
\text { CHILE (OLAVARRIETA ET AL. 2001) }\end{array}$} & \multicolumn{4}{|c|}{$\begin{array}{c}\text { PART B) } \\
\text { US (HENDERSON AND COTE 1998) }\end{array}$} \\
\hline & R2 (\%) & ADJ. R2 & $\begin{array}{l}\text { SIGNIFICANT } \\
\text { DESIGN } \\
\text { VARIABLES IN } \\
\text { CHILE }\end{array}$ & $\begin{array}{c}\text { TYPE OF } \\
\text { RELATIONSHIP }\end{array}$ & $\begin{array}{l}\mathrm{R} 2 \\
(\%)\end{array}$ & ADJ. R2 & $\begin{array}{c}\text { SIGNFICANT } \\
\text { LOGO DESIGN } \\
\text { VARIABLES IN } \\
\text { US }\end{array}$ & $\begin{array}{c}\text { TYPE OF } \\
\text { RELATIONSHIP }\end{array}$ \\
\hline $\begin{array}{l}\text { Correct } \\
\text { recognition }\end{array}$ & 60.3 & 33.8 & $\begin{array}{l}\text { Natural } \\
\text { Repetition } \\
\text { Round }\end{array}$ & $\begin{array}{l}\text { Linear, positive } \\
\text { Linear, positive } \\
\text { Curve, } \cap\end{array}$ & 31.4 & 27.7 & $\begin{array}{l}\text { Natural } \\
\text { Repetition } \\
\text { Harmony } \\
\text { Affect }\end{array}$ & $\begin{array}{l}\text { Linear, positive } \\
\text { Linear, positive } \\
\text { Curve } \cap \\
\text { Linear, positive }\end{array}$ \\
\hline $\begin{array}{l}\text { False } \\
\text { recognition }\end{array}$ & 42.4 & 17.8 & $\begin{array}{l}\text { Parallel } \\
\text { Elaborate } \\
\text { Round }\end{array}$ & $\begin{array}{l}\text { Curve } \cap \\
\text { Curve } \cup \\
\text { Linear, negative }\end{array}$ & 22.7 & 18.5 & $\begin{array}{l}\text { Parallel } \\
\text { Natural } \\
\text { Harmony } \\
\text { Proportion }\end{array}$ & $\begin{array}{l}\text { Curve } \cap \\
\text { Linear, negative } \\
\text { Linear, positive } \\
\text { Curve } \cap\end{array}$ \\
\hline Affect & 74.3 & 59.5 & $\begin{array}{l}\text { Harmony } \\
\text { Proportion } \\
\text { Repetition }\end{array}$ & $\begin{array}{l}\text { Curve } \cap \\
\text { Curve, } \cup \\
\text { Linear, positive }\end{array}$ & 60.3 & 58.6 & $\begin{array}{l}\text { Harmony } \\
\text { Elaborate } \\
\text { Natural }\end{array}$ & $\begin{array}{l}\text { Linear, positive } \\
\text { Curve } \cap \\
\text { Curve } ?\end{array}$ \\
\hline Meaning & 46.9 & 27.5 & $\begin{array}{l}\text { Parallel } \\
\text { Harmony } \\
\text { Proportion }\end{array}$ & $\begin{array}{l}\text { Curve } \cap \\
\text { Linear, positive } \\
\text { Linear, negative }\end{array}$ & 24.6 & 21.4 & $\begin{array}{l}\text { Proportion } \\
\text { Natural }\end{array}$ & $\begin{array}{l}\text { Curve } \cap \\
\text { Linear, positive }\end{array}$ \\
\hline
\end{tabular}

When comparing the results of the Chilean study and the US-based study, interesting similarities and differences can be identified. Generally speaking, correct recognition is the response variable most 
valued and emphasized when designing logos according to existing design and marketing literature. It is interesting to notice how correct recognition can be influenced by natural and repetitive designs in both the US and in Chile. Both design characteristics have positive linear relationships with correct recognition. False recognition, can also be enhanced in both nations by the use of logo designs that have a medium level of parallel lines.

Another common factor in the US and Chile studies, is the importance of harmony in order to generate positive affect. In the case of the US, harmony is positively related to affect, and in the case of Chile, an inverse u-shaped relationship was found also suggesting that medium-levels of harmony (i.e., balance and symmetry) will positively influence logo and brand affect. Finally, for generating familiar meanings, proportion is a significant design characteristic in both nations, presenting an inverse u-shaped relationship with familiar meaning. In other words, very low or very high proportion can harm the generation of familiar meanings. This can be related to consumers' experiences. One would expect that, in both nations, very disproportionate and highly proportionate logos, will be the less common or "familiar" type of logos.

One important difference between the US and Chilean study is that in the North-American study, the independent design variable "natural" was a significant variable in all four regression models, while in the Chilean study, it was significant only in one (e.g. correct recognition). This result is particularly striking for the meaning regression model. It would suggest that "natural" designs can, in fact, generate different meanings for Chilean consumers. One reason could be that Chilean consumers are more creative when processing natural visual cues, triggering different and deeper layers of associations. Another explanation, could be that Chileans normally have a larger number of associations or metaphors linked to natural elements. Finally, this could also be related to language and language use, as suggested by Schmitt and Zhang (1998). In Spanish, natural designs can trigger a particular word that can be used in more 
different ways and contexts (meanings) than in English. On the other hand, and interestingly enough, round was found significant in both the correct and false recognition regression models for the Chilean case, but in none of the US regression models.

\section{Conclusion and discussion}

The overall conclusion is that the logo design characteristics identified in the US-based literature, do affect consumer responses on a cross-cultural setting, thus adding value to the original framework. There are certain variable though, that behave differently than expected when studied in an overseas setting. This would then seem to indicate that, not only is further analysis on this data warranted, but also, that the topic needs to be further explored under other cultural and market characteristics, so as to be able to provide practitioners and academics with some normative guidance in what seems to be an active area of business activity.

Since design can be an important driver of Marketing ROI (Wallace 2001), it is very important for business, marketing and design researchers to develop more scientific studies of the effects of design characteristics on consumers perceptions, evaluations, and eventually, financial or business performance. This piece of research is a starting point, that shows that this might be possible, and that aesthetics is not just a pure subjective task. From a theoretical point of view, two important lessons can be learned from this study. First, communication and advertising theories can be used also to explain design characteristics effects. For example, element repetition is positively associated with correct recognition, something normally suggested in the advertising literature. Further theoretical integration and development is needed in the design arena. Additionally, aesthetics might be influenced by culture, but some generalities might be present in different cultures. This is important, not just for the design and marketing literature, but for cross cultural 
psychologists and sociologists, caring about emic and etic phenomena, and for globalization studies.

We suggest, that this might be an important stream of research in the future, exploring the role of forms and ergonomics, product materials, building and architectural store design elements, etc. on consumer perceptions and value creation. Cross disciplinary research can be a key research strategy to improve understanding of these issues.

\section{References}

AAKer, D. (1991), "Managing Brand Equity: Capitalizing on the value of a Brand Name" New York: The Free Press.

ASlam, M. M. (2006), "Are you selling the right colour? A cross-cultural review of colour as a marketing cue", Journal of Market Communications, 12 (1), pp. 15-30.

Berlyne, D. E. (1971), "Aesthetics and Psychobiology" (New York: Meredith Corporation).

Berlyne, D.E. (Ed.) (1974), "Studies in the new experimental aesthetics: Steps toward an objective psychology of aesthetic appreciation" (New York: Wiley).

Bloch, P. H. (1995), "Seeking the ideal form: product design and consumer response", Journal of Marketing, 59 (July), pp. 16-29.

Bloch, P. H., F.F. Brunel and T.J. ARnOld (2003), "Individual differences in the centrality of visual product aesthetics", Journal of Consumer Research, 29 (4), pp. 551-565.

DRESCHER, T. D. (1992), "The transformation and evolution of trademarks - from signals to symbols to myth", The Trademark Reporter (May-June), pp. 301-340. 
Giberson, R. and J. Hulland (1994), "Using logos as cues to recognition: a preliminary study", Ivey Business School Working Series Papers $\mathrm{N}^{\mathrm{o}}$ 94-24 (October).

Henderson, P. and J. Cote (1998), “Guidelines for selecting or modifying Logos", Journal of Marketing, 62 (April), pp. 14-30.

KELLER, K.L. (1993), “Conceptualizing, measuring and managing customer-based brand equity", Journal of Marketing, 57 (January), pp. 1-22.

Keller, K.L. (2002), “Strategic Brand Management” $2^{\text {nd }}$. Ed., Prentice Hall, New Jersey.

Madden, T.J., K. HewitT and M.S. Roth (2000), "Managing images in different cultures: a cross-national study of color meanings and preferences", Journal of International Marketing, 8 (4), pp. 90-105.

Messinger, S.M. (1998), "Pleasure and complexity: Berlyne Revisited", The Journal of Psychology, 132 (5), pp. 558-560.

Nicholls, J.A., F.F. Li, T. Mandakovic, S. Roslow and C.J. Kranendonk (2000), "US-Chilean mirrors: shoppers in two countries", Journal of Consumer Marketing, 17 (2), pp. 106-119.

Peter, J. (1989), “Designing logos”, Folio, 18 (July), pp. 139-41.

SCHECHTER, A. H. (1993), "Measuring the value of corporate and brand logos", Design Management Journal, 4 (1), pp. 33-39.

Schmitt, B. H., A. Simonson and J. MARCus (1995), "Managing corporate image and identity", Long Range Planning, 28 (5), pp. 82-92.

SCHMITT, B. H. and Y. Pan (1994), "Managing corporate image and identity in the Asia-Pacific region”, California Management Review, 36 (4), pp. 32-48. 
SCHMITT, B. H. and S. ZHANG (1998), "Language structure and categorization: a study of classifiers in consumer cognition, judgement and choice", Journal of Consumer Research, 25 (September), pp. 108-122.

TAVAssoli, N. T. and J.K. HAN (2002), "Auditory and visual brand identifiers in Chinese and English”, Journal of International Marketing, 10 (2), pp. 13-28.

Wallace, R. (2001), "Proving our Value: Measuring Package Design's Return on Investment”, Design Management Journal, 12 (3), pp. 20-27.

ZAJONC, R. B. (1968), “Attitudinal effects of mere exposure”, Journal of Personality and Social Psychology, 9 (2, part 2), pp. 1-27.

Graphis World Trademarks: 100 Years (1998), ed. Rick Eiber, Xenia Press. 